\title{
Identifying the need for pasture renewal and valuing the contribution of renewal on a dairy farm - Telford Dairy, a case study
}

\author{
D.R. STEVENS ${ }^{1}$ and I. KNOWLES ${ }^{2}$ \\ ${ }^{1}$ AgResearch Invermay, Private Bag 50034, Mosgiel \\ ${ }^{2}$ Telford Rural Polytechnic, P.O. Box 6, Balclutha \\ david.stevens@agresearch.co.nz
}

\begin{abstract}
How do we know which pastures to renew and do we increase profitability when we renew them? An inventory of pasture production of the Telford dairy farm was developed using paddock grazing records to estimate potential pasture production and variability from different soil types. Using the difference between low and high producing pastures as the potential for improvement, the change in pasture production with renewal was calculated and valued using several methods, from the simple conversion of extra dry matter into milk solids production through to whole farm systems optimisation using Farmax Dairy Pro. The cost of pasture renewal was highest when valued by the Pasture Renewal Charitable Trust model when the cost of lost grazing was estimated. The return for pasture renewal was lowest from Farmax Dairy Pro modelling when whole farm-integration was considered. At the average value of milk for the last 5 years, the payback period was between 2.5 and 3.1 years, depending on the model used.
\end{abstract}

Keywords: analysis, modelling, pasture production records, pasture renewal, soil types.

\section{Introduction}

Cocks \& Brown (2006) stated that recent changes in the sheep, beef and dairy industries have precipitated a need for further efficiencies of production to be explored in the face of rising costs and reduced returns. An example of the goals set for the dairy farming industry came from Dairy_Insight (2006). "The dairy industry will increase dairy farmer profitability and create wealth for the New Zealand economy through achieving, by 2015 , a $50 \%$ total productivity increase ( $4 \%$ p.a.) and a $35 \%$ growth in milk solids (3\% p.a.)." Green (2005) placed the progress in on-farm productivity in perspective noting that milksolids per cow had increased $44 \%$ since 1975.

The gains in pasture productivity from pasture renewal have been assumed to be an important part of achieving these goals. However, Caradus (2006), in reviewing 75 years of technological advances in pastoral agriculture, stated that the rates of pasture renewal have not changed markedly since the 1930s.
The question then remains: if pasture renewal does lead to greater net wealth on the farm, shouldn't we be doing more of it?

Dairy farmers often record paddock covers. However, these records are seldom kept for further use after immediate decisions about cow feeding and pasture management. Examining these records can provide an insight into the opportunities that may occur to help improve overall farm productivity, increasing pasture growth and reducing costs such as silage making. The data can also help understand the characteristics of different parts of the farm to improve pasture management. Finally, records can assist in the decision to renew pastures.

The paper outlines the process of identifying pastures that may need renewal and uses several different methods of valuing the outcomes of that pasture renewal using the Telford dairy farm as a case study.

\section{Methods}

Since 2007/08 DairyNZ has supported the Telford Polytechnic dairy unit (Balclutha, Otago) as a demonstration farm to identify and demonstrate local issues in the dairy industry.

\section{The farm}

The Telford dairy unit comprises a total area of 175 ha of which 170 ha is effective, in 78 paddocks. Approximately 525 cows are farmed on the milking platform at a stocking rate of 3.1 cows/ha. Cows are dried off by mid May and come back to the farm in calving groups from mid July onwards with extensive use of calving pads and feed pads from early August. The mean lactation length is 268 days with a mean production ranging between 360 and $375 \mathrm{~kg}$ MS/cow.

The farm is almost equally divided into two major soil classifications. The Tokomairiro and Te Houka deep silt loams are classified as Fragic Pallic soils with a slow permeability resulting in imperfect drainage. Artificial drainage in the form of mole and tile drainage is in place. The Puerua and Parata deep peaty loams are classified as mellow Mesic Organic soils. These soils have moderate permeability but poor natural drainage due to the high water table, but drainage is 
Figure 1 Daily pasture production estimates each month for the Telford Dairy farm from the Pallic and Organic soil types of the farm.

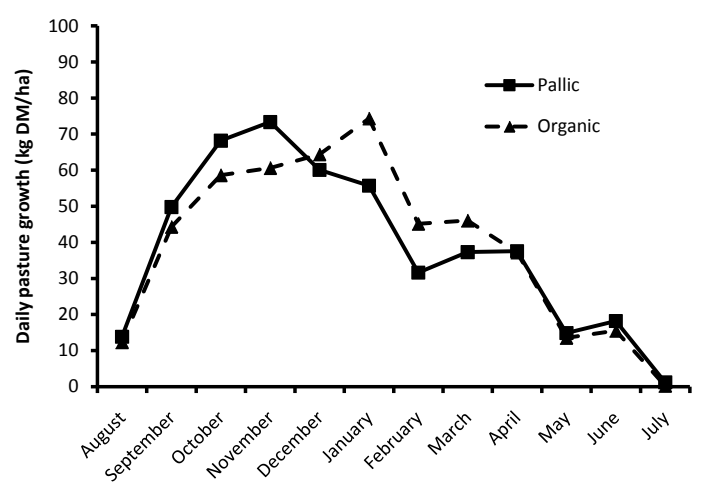

supplemented by open drains at $50 \mathrm{~m}$ spacings.

\section{Pasture production estimates}

The farm paddock grazing records for the whole farm were collected for both the 2007-08 and 2008-09 milking seasons and included weekly pasture cover in each paddock, pre- and post-grazing covers and the number of cows grazing each paddock at every grazing of that paddock. Cover was recorded by rising plate meter or by eye estimation. These records were then used to determine the amount of pasture utilised in every paddock and the pasture growth rate of the paddocks between grazings. Pasture quality was also measured on the next paddock to graze at 7- to 14-day intervals throughout the 2008/09 milking season from mid August to mid May.

Pastures were then given a production rank of low $(<10,000 \mathrm{~kg} \mathrm{DM} / \mathrm{ha})$, medium $(10,000$ to $13,000 \mathrm{~kg}$ $\mathrm{DM} / \mathrm{ha})$ or high $(>13,000 \mathrm{~kg} \mathrm{DM} / \mathrm{ha})$ based on the total amount of pasture utilised per annum, and assigned to either Pallic or Organic soil type.

\section{Assigning a value to pasture renewal}

Three methods were used to assign a value to the benefits of pasture renewal. The first method used was the Cost-benefit Calculator in the ForageMaster software package (Beef+LambNZ 2008). This calculator provides the user with the opportunity to input current and future data for pasture production ( $\mathrm{kg} \mathrm{DM} / \mathrm{ha} /$ annum), pasture utilisation (\%) and pasture quality (MJME $/ \mathrm{kg}$ DM). The value of feed is expressed as c/MJME, again as an input by the user. Pasture renewal cost $(\$ / \mathrm{ha})$ is also designated by the user. The calculator then provides a measure of the value of the renewal for the 2 years after renewal.

The second method used was the Pasture Renewal Charitable Trust Dairy spreadsheet (PRCT 2009). Establishment cost was determined using expert opinion of best practice and current input prices for seed, fertiliser, insecticides and herbicides.

In both of these cases it was assumed that pastures in the low category were improved to match those in the high category of pasture production. Assumptions for the models are recorded in Table 1, including the pasture renewal costs.

The final method used was a whole farm modelling with the Farmax Dairy Pro (Bryant et al. 2010) decision support model that uses monthly estimates of pasture growth, farm and herd information to determine production and economic responses from on-farm decisions.

In this study, the Telford dairy farm was used as the case study and the base model developed from current practices and calibrated to current performance. The current actual costs of production were used in the model. A summer turnip crop of 6 ha is a feature of the current farming practice and was continued through all models. The base model used the pasture production information from the paddock records and six blocks were created on the farm to represent the average of the pasture types that were identified. These were firstly the two soil types, Pallic or Organic, and each of these was subdivided into low, medium or high production with the allocation of area to each from the pasture records (as per 'Pasture production estimates').

Five pasture renewal models were applied to the farm. These were all single-year status quo models.

- Renewal of all of the poor pasture on the Pallic soil type in a single year to assess the establishment cost to change the system.

- Long term outcome of improving the poor pastures on the Pallic soils.

- Renewal of all of the poor pastures on the Organic soil type in a single year

- Long term outcome of improving the poor pastures on the Organic soil

- Long term outcome of renewing all poor pastures on both soil types

The following assumptions were made in the Farmax Dairy Pro modelling.

- Pastures were improved by grass-to-grass renewal using cultivation

- The area to renew was divided in three and renewal was initiated at three-week intervals from mid spring to early summer

- Each area was out of production for 8 weeks

- The feed deficit created was filled using extra nitrogen $(\mathrm{N})$ fertiliser on the rest of the farm

- Post-renewal pasture production was assumed as that of the high production pastures

- The increase in pasture production was utilised using an increase in stocking rate and making 
Table 1 Key assumptions made about pasture production and pasture renewal costs for modelling pasture renewal value.

\begin{tabular}{|c|c|c|c|}
\hline \multicolumn{2}{|l|}{ Assumptions } & \multirow[t]{2}{*}{ Organic soil types } & \multirow[t]{2}{*}{ Pallic soil types } \\
\hline Pasture utilised & (kg DM/ha/annum) & & \\
\hline & Low & 9190 & 8350 \\
\hline & Medium & 11590 & 11570 \\
\hline & High & 14440 & 13930 \\
\hline Lost feed during renewal ${ }^{1}$ & (kg DM/ha) & 3170 & 3220 \\
\hline Opportunity cost of lost feed & $\mathrm{PRCT}^{2}$ & \multicolumn{2}{|c|}{$23 \mathrm{c} / \mathrm{kg} \mathrm{DM}$} \\
\hline Value of feed & ForageMaster ${ }^{3}$ & \multicolumn{2}{|c|}{3.78 c/MJME } \\
\hline Pasture quality & (MJME/kg DM) & \multicolumn{2}{|c|}{12} \\
\hline \multirow[t]{3}{*}{ Feed requirement for milk production } & PRCT Old pasture (kg DM/kg MS) & \multicolumn{2}{|c|}{13.8} \\
\hline & PRCT New pasture (kg DM/kg MS) & \multicolumn{2}{|c|}{13.2} \\
\hline & ForageMaster (MJME/kg MS) & \multicolumn{2}{|c|}{150} \\
\hline Milk price (average for past 5 years) & & \multicolumn{2}{|c|}{$\$ 5.67$} \\
\hline \multirow[t]{7}{*}{ Cost of renewal (grass to grass) } & Pre-cultivation herbicide & \multicolumn{2}{|c|}{$\$ 79$} \\
\hline & Cultivation (five passes) & \multicolumn{2}{|c|}{$\$ 295$} \\
\hline & Seed (AR1 ryegrass/white clover, incl. sowing) & \multicolumn{2}{|c|}{$\$ 253$} \\
\hline & Lime plus fertiliser (incl. spreading) & \multicolumn{2}{|c|}{$\$ 248$} \\
\hline & Post-emergence weed spray & \multicolumn{2}{|c|}{$\$ 93$} \\
\hline & Post emergence $\mathrm{N}$ & \multicolumn{2}{|c|}{$\$ 70$} \\
\hline & Total/ha & \multicolumn{2}{|c|}{$\$ 1,037$} \\
\hline \multirow[t]{7}{*}{ Cost of summer crop } & Pre-cultivation herbicide & \multicolumn{2}{|c|}{$\$ 79$} \\
\hline & Cultivation (five passes) & \multicolumn{2}{|c|}{$\$ 295$} \\
\hline & Seed (Barkant turnip, incl. sowing) & \multicolumn{2}{|c|}{$\$ 95$} \\
\hline & Lime plus fertiliser (incl. spreading) & \multicolumn{2}{|c|}{$\$ 244$} \\
\hline & Post-emergence pest spray & \multicolumn{2}{|c|}{$\$ 38$} \\
\hline & Post emergence $\mathrm{N}$ & \multicolumn{2}{|c|}{$\$ 70$} \\
\hline & Total/ha & \multicolumn{2}{|c|}{$\$ 821$} \\
\hline \multirow[t]{6}{*}{ Cost of renewal (post-crop) } & Cultivation (three passes) & \multicolumn{2}{|c|}{$\$ 135$} \\
\hline & Seed (AR1 ryegrass/white clover) & \multicolumn{2}{|c|}{$\$ 253$} \\
\hline & Fertiliser (incl. spreading) & $\$ 8$ & \\
\hline & Post-emergence weed spray & $\$ 9$ & \\
\hline & Post emergence $\mathrm{N}$ & $\$ 4$ & \\
\hline & Total/ha & $\$ 6$ & \\
\hline Timing & Spray & mid-Nor & mber \\
\hline & First grazing & mid-Ja & uary \\
\hline
\end{tabular}

${ }^{1}$ Lost feed during renewal - pasture that would have been grown on the paddock chosen for renewal (based on the pasture growth rates of the poor pastures identified by the paddock records) from the start of renewal in mid November until the return to grazing in mid January.

${ }^{2}$ PRCT - Pasture renewal worksheet for dairy farms - Pasture Renewal Charitable Trust

${ }^{3}$ ForageMaster pasture renewal value calculator - Beef + Lamb NZ 
more silage on-farm, replacing bought in silage. It was also used to offset $\mathrm{N}$ fertiliser use. These management options were seen as appropriate to the current management skills on the farm.

A simple payback period was calculated for each model using the equation

Payback period $=$ Cost of renewal $/$ net return per year

\section{Results and Discussion}

\section{Variations in pasture productivity}

The mean of 2 years of data from Telford (Fig. 1) shows the variations between the two predominant soil types of the farm. The Pallic soils had higher pasture growth rates in spring as those soil types were less prone to spring water-logging due to a rolling topography, but are more prone to drying out in the summer (Fig. 1). This was more pronounced in the summer of 2007/08, which was significantly drier than usual. The Organic soils had a higher growth rate during summer (Fig. 1) due to the high water table. No differences were noted in the autumn.

An analysis of the data, done by categorising the paddocks into low ( $<10 \mathrm{t} \mathrm{DM} / \mathrm{ha} /$ annum $)$, medium (10-13 t DM/ha/annum) or high ( $>13 \mathrm{t} \mathrm{DM/ha/annum)}$ pasture production (from the 2008/09 records), showed that the relative differences in monthly growth rates between the categories were similar for both the Pallic and the Organic soils, so combined data are shown

Figure 2 Daily pasture production estimates each month of low, medium and high producing pastures on the Telford Dairy farm. Data are means of 2 years.

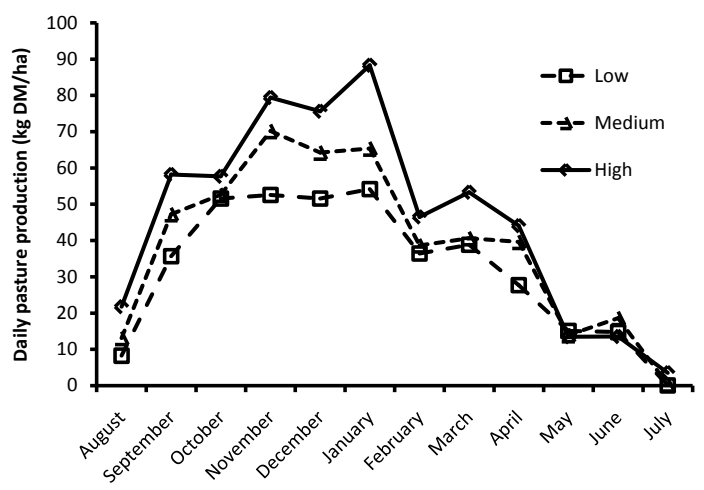

(Fig. 2); similar seasonal growth patterns to the general trends were exhibited by the three areas.

Comparison of the relative annual performance of paddocks showed that the mean difference between the two soil types was approximately $1 \mathrm{t} \mathrm{DM} / \mathrm{ha} /$ annum (Fig. 3). There was also a greater percentage of paddocks in the low production category on the Pallic soils than the Organic soils. Mean pasture production for the categories (Table 1) indicated that the medium and high production pastures were relatively similar in average yield, but the low production category had a lower yield on the Pallic soils than the Organic soils. The data presented in Fig. 3 reflect the degree of variation found in Waikato dairy pastures (Clark et al. 2010) where the poorest pasture produced approximately half of the best pasture on commercial farms.

\section{Improving poor performing pastures}

Low producing paddocks made up a significant part of both soil type areas of the farm (Table 2) accounting for 37 of the 87 ha of the Pallic soil types analysed and 20 of the 77 ha of the Organic soil types analysed. Only 31 ha of the Pallic soils were included in the Farmax Dairy Pro modelling as 6 ha of the Pallic soils were assigned to summer turnips each year.

The use of the three models to value the benefits of pasture renewal (Fig. 4) showed a clear distinction between the methods used. The value of renewal decreased as the models became more elaborate. Simple costs of renewal (calculated using the Pasture Renewal Charitable Trust model) were applied to all models for consistency. The addition of a cost for the loss of grazing in the PRCT model led to this model having the highest costs in the establishment year. The cost of renewal in the Farmax Dairy Pro model was calculated as the combined cost of both renewal and other feed sources that were required to fill the feed gap, such as $\mathrm{N}$ fertiliser and silage use, while maintaining cow numbers. This strategy proved to be less costly than the PRCT estimates, when feed supply over the whole farm was considered.

The value of the pasture renewal also varied significantly depending on the complexity of the model. The simple ForageMaster calculator provides no

Table 2 Outcomes from Farmax Dairy Pro modelling of improving pasture production on the Telford Dairy farm.

\begin{tabular}{lcccccc}
\hline Farm System & $\begin{array}{c}\text { Area im- } \\
\text { proved }(\mathrm{ha})\end{array}$ & $\begin{array}{c}\text { Milk Solids } \\
(\mathrm{kg})\end{array}$ & Profit (\$) & $\begin{array}{c}\text { Increase per ha } \\
\text { improved }(\$)\end{array}$ & $\begin{array}{c}\text { MS/cow } \\
\text { Number of } \\
\text { Cows }\end{array}$ \\
\hline Current & 0 & 203,494 & 468,621 & - & 388 & 530 \\
Improve Pallic soils & 31 & 208,489 & 486,303 & 571 & 390 & 540 \\
Improve Organic soils & 20 & 205,700 & 476,244 & 381 & 468 & 535 \\
Improve All & 51 & 209,840 & 492,214 & 469 & 545 \\
\hline
\end{tabular}


Figure 3 The frequency distribution of pasture production on the Pallic and Organic soil types of the Telford Dairy farm.

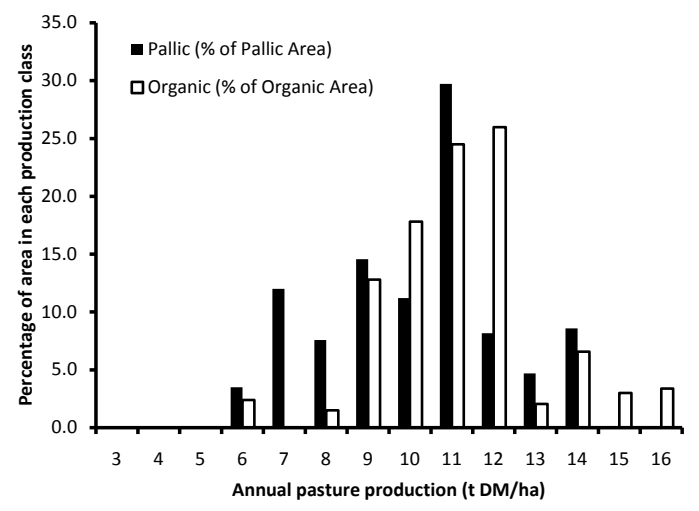

opportunity to assign a production cost to the extra milk produced, so it is up to the user to value the extra energy produced. This generally leads to an overestimation of the value of renewal. An allowance for increased cost of production is provided for in the PRCT model and this value was derived from the Farmax Dairy Pro modelling to ensure consistency between the two. A value of $38 \%$ of the extra production was assigned as a direct production cost. The key difference between the Farmax Dairy Pro approach and the PRCT approach was the ability of the Farmax Dairy Pro model to integrate the monthly pasture production data across the whole farm area, including the other soil types and pasture production categories. When integrated in this way the added feed has a much lower value. Extra pasture production was utilised mostly by increasing cow numbers in the Farmax model. Savings were made by less $\mathrm{N}$ use and less bought-in silage to fill feed deficits.

The assumptions made in the Farmax Dairy Pro modelling were to allow the extra production to be accounted for by changes in $\mathrm{N}$ use, silage making and adding extra cows. Other modelling work has indicated that feeding the cows more pasture can be more economic use of the extra feed grown (Bryant et al. 2010). The current modelling exercise took the approach of utilising the current skills of the management team rather than assuming that staff would increase their skill base to enable better feeding.

The Farmax Dairy Pro model predicted that the long term benefits were greater from improving the Pallic soils than the Organic soils. This was due to the increase in early spring pasture production from improving the Pallic soils (Fig. 1). This led to lower silage feeding at this time and increased on-farm silage making, offsetting bought-in silage.

Regardless of the model chosen, the value of pasture renewal was positive. The ForageMaster model
Figure 4 A comparison of the cost and net income in the establishment year and the following year from pasture renewal using three models of different complexity.

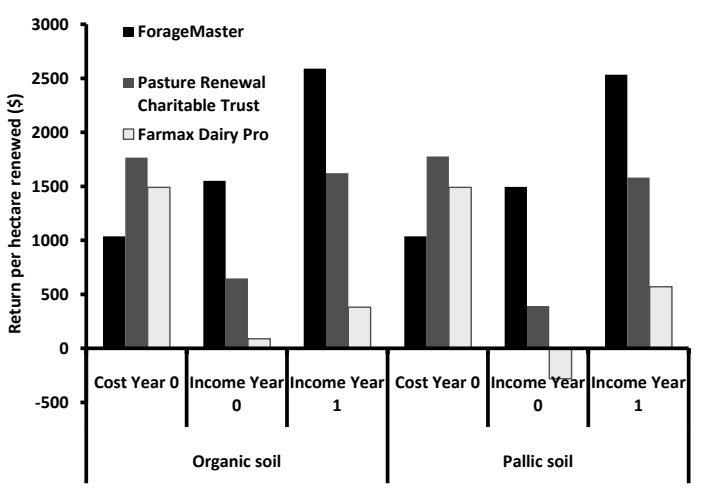

predicted a full payback of investment within 1 year, while the PRCT model predicted a payback for both soil types of approximately 2.7 years. The payback period using Farmax Dairy Pro was 3.1 and 3.7 years on the Organic and Pallic soils respectively, but ongoing income was much lower using Farmax Dairy Pro than the PRCT model. The payback periods were also calculated using a payout of $\$ 3.50 / \mathrm{kg}$ MS for both the PRCT and Farmax Dairy Pro models. In the case of the PRCT model this increased the payback period to 3.5 years for both soil types, while it extended it to 9.1 years for both the Organic and Pallic soils using Farmax Dairy Pro.

Pasture production records are taken on many farms and provide an opportunity to make improved on-farm decisions about pasture renewal. The relative variation between high and low producing pastures provides an insight into the profitability of pasture improvement. However, the key to on-going profitability is the longevity of the difference achieved from renewal.

The use of various models can aid in the decisions to make pasture renewal decisions, but the assumptions that are made are important when ensuring that these estimates are valid. The changes in the production of a single paddock may not have the impact on the whole-farm system that a simple calculation might indicate. Taking into account the changes in monthly production as well as total production can help improve the accuracy of the estimates of the value of pasture renewal.

At the current cost of approximately $\$ 1,000 /$ ha to renew pastures, the increased performance of a new pasture needs to last approximately 3 years at least to break even. The rate of reversion of pastures back towards the average and then potentially to the original state of the pasture will depend on the actual needs of the pasture. If drainage and increased base fertility are 
fixed during the renewal process then this will help longevity. If the problems were pasture management related (e.g. pugging damage or over-grazing) then some change in management practice may be required to avoid this in the future.

\section{Conclusions}

In conclusion, the analysis of pasture performance provides a starting point to examine the role of pasture renewal and pasture management in productivity. Identification of the cause of decline in pasture production is essential to ensure future gains in production can be sustainable. Pasture renewal programmes need to target the poor performing pastures and then should provide a significant increase in both production and profitability. The costs of pasture renewal can be justified, as long as the increases in pasture production are captured in animal performance.

Modelling provides a guide to the economics of pasture renewal, with more complex models providing more realistic estimates of the value of pasture renewal.

\section{ACKNOWLEDGEMENTS}

The authors wish to acknowledge DairyNZ for funding the project and Zac Haderbache and Telford farm staff for collecting the paddock records.

\section{REFERENCES}

Beef+LambNZ 2008. How to Resources: ForageMaster. Manual/CD-ROM. Beef + Lamb NZ.

Bryant, J.R.; Lambert, M.G.; Brazendale, R.; Holmes, C.W.; Fraser, T.J. 2010. Effects of integrated cropping and pasture renewal on the performance and profit of dairy farms. Proceedings of the New Zealand Grassland Association 72: 29-34.
Bryant, J.R.; Ogle, G.I.; Marshall, P.R.; Glassey, C.B.; Lancaster, J.A.S.; Garcia, S.C.; Holmes, C.W. 2010. Description and evaluation of the Farmax Dairy Pro decision support model. New Zealand Journal of Agricultural Research 53: 13-28.

Caradus, J.R. 2006. 75 years of scientific and technological advances in pastoral agriculture - what will it take to continue to deliver? Proceedings of the New Zealand Grassland Association 68: 33-68.

Clark, C.E.F.; Romera, A.J.; Macdonald, K.A.; Clark, D.A. 2010. Inter-paddock annual dry matter yield variability for dairy farms in the Waikato region of New Zealand. New Zealand Journal of Agricultural Research 53: 187-191.

Cocks, J.; Brown, C. 2006. Long-term analysis of price, productivity, and profitability trends in New Zealand agriculture. Proceedings of the New Zealand Grassland Association 67: 9-18.

Dairy_Insight 2006. Annual Report 2005-2006. Accessed February 2010. www.dairyinsight.co.nz/ publications/-annual-reports.php. Dairy Insight.

Green, R. 2005. Constant evolution to ensure a successful future. Proceedings of the New Zealand Grassland Association 67: 1-7.

PRCT 2009. The power of pasture renewal. Accessed 1 February 2011. http://www.pasturerenewal.org.nz/article/37.html. Pasture Renewal Charitable Trust. 